\title{
Engineering Geological and Geophysical Assessment of the 2009 Jiwei Shan Rockslide, Wulong, China
}

\author{
Ez Eldin ${ }^{1^{*}}$, M. A. M., Huiming Tang ${ }^{2,3}$, Yixian $\mathrm{Xu}^{1}$, Chengren Xiong ${ }^{3}$, Yunfeng $\mathrm{Ge}^{2}$ \\ ${ }^{1}$ Institute of Geophysics \& Geomatics, China University of Geosciences, Wuhan, China \\ ${ }^{2}$ Faculty of Engineering, China University of Geosciences, Wuhan, China \\ ${ }^{3}$ Three Gorges Research Center for Geohazard, Ministry of Education, China University of Geosciences, Wuhan, China \\ Email: *mutasimadam@hotmail.com
}

Received 2013

\begin{abstract}
This study presents the engineering geological and geophysical assessment of the June 5, 2009 Jiwei Shan rockslide, Wulong, China. Jiwei Shan is a part of Wulong karst terrain lithologically, it's composed of Quaternary Deposits, Jialingjiang Formation, Maokou, Qixia, Liangshan and Hanjiadian Groups (chronologically from younger to older). The surface is highly irregular (pinnached), the rocks contain two sets of fractures, networks of convoluted solution channels and caves and there are large voids filled by soil mantle. It's a south-north dipping limb of an anticline fold composed of sedimentary rocks, mainly of limestone of variable composition, mudstone and shale and series of limestone deposited with interbedded mudstone and shale. There are two sets of steeply dipping fractures developed in the Maokou and upper strata of Qixia Groups; set one trending EW and set two trending nearly SN directions. The study has been conducted by geological fieldwork, geophysical investigation (Vertical Electrical Sounding), petrographical and scanning electron microscope (SEM) studies and laboratory testing on rock samples collected from Jialingjiang Formation and Maokou and Qixia Groups. The study of the SEM photomicrographs showed that the microcrack propagations in limestone indicated that the increases in crack length and micropores of limestone are indication to the weathering grade increase from II (slightly weathered rock) to grade III and IV (moderately and highly weathered, respectively). The Qixia Group; Middle Layer is highly weathered shale and bituminous interlayer with clear fissility, high porosity, and gently dipping strata, it represents the sliding surface of the rockslide. It's comparatively weak and strongly weathered compared to the overlain EW and SN fractured stratum. Generally, the tectonic of the study area imposes controls on the rockslide in many ways: created favourable terrain, provided sufficient rockslide prone materials such as highly weathered limestone and shale, weak rocks, created very steep beds which reduced the stability of the highly fractured bedrock of the slope.
\end{abstract}

Keywords: Lithology; Fractures; Weathering; Jiwei Shan Rockslide; Laboratory Tests

\section{Introduction}

In spite of rockslides and avalanches occurring often in remote mountainous areas, they still draw a lot of attentions of many researchers, because it is hard to predict and frequently result in great damage. Most rockslides in high mountainous areas often evolved into rapid moving blocks and debris flows, traveling over long distances and causing serious and sudden destruction of considerable large areas [1]. This rockslide is predisposed by tectonic, geological structures, lithology, topography and rainfall. Earthquake may also play an indirect way. The movement of rockslide is largely controlled by the topographic condition and slope geometry of the area; in turn it influenced the mobile behaviour of the rockslide. Massive rock slope with inclined thick bedding structure

${ }^{*}$ Corresponding author. is widely distributed in the southwestern carbonate rock areas of China and the failure pattern is conventionally recognized as lateral fall or topples with a short runout distance. Due to the presence of a front a stable bedrock towards the north of the moving block as in Jiwei Shan, the rockmass laterally falls or topples first and subsequently accumulates on the lower gentler slope, secondary rockslide will induced by trigger factor such as rainfall, earthquake, ...etc leading to a long distance runout and accumulation [2] (Figure 1).

[3] simulates the movement process of Jiweishan rockslide and [4] analyzed the geological conditions and mining exploitation, the new failure pattern of inclined thick bedding slope under gravity, karst and mining process by adopting the $\mathrm{PFC}^{\mathrm{BD}}$ simulation to of Jiweishan rockslide. The preliminary investigation carried out by [1] revealed that, Jiwei Shan rockslide with poor geological 
conditions was mainly induced by the gravitation and the karst effect and also affected by the previous mining activities.

Jiwei Shan rockslide is located in Chongqing, Wulong County; Tiekuang town; Hongbao village. It's about $75 \mathrm{~km}$ southwest of Wulong County (Figure 2). Wulong County greatly suffered from geological disasters. Landslides, rockfalls, ground subsidences and ground fissures take place frequently and cause a lot of economic loss and casualties, furthermore the sustainable development of society and economy is restrained. In spite of these geological disasters, there are a few studies has been conducted in the study area. It is situated in subtropical moist monsoon climate of middle latitude, easily affected by the season changing. It's warm and wet with plentiful rainfalls.

The regional seismic activity in Chongqing and the surrounding counties it belongs to the medium level, and the largest earthquake in the history is not more than the magnitude of six [5]. The shallow epicentre of the earthquake lead to strongly feeling of the shake, it caused the serious economic losses in spite that, the intensity of the earthquake is not too high. Generally, Chongqing and the surrounding counties are not in the level of high seismic activity but it may affected by earthquake coming from areas of high seismicity such as Sichuan Province.

Jiwei Shan extends along the SN direction, with eastern 50 - $150 \mathrm{~m}$ cliff. The maximum and minimum height of Jiwei Shan at elevations of 1,442 and 1,000 m (asl), respectively, and a height difference of $442 \mathrm{~m}$. It exhibits an undulating terrain formed by long term denudation and plantation. At 03:00 PM, 5 June, 2009 Jiwei Shan rockslide originated as a free fall (toppled) from the east creek face, followed by second failure on rock mass originated from a platform extends from south to north and dip $30^{\circ}$ towards the north. The slided material traveled over the valley, it further entrained amount of debris in its path as it was transformed into a rapidly moving rock-debris flow over the valley, and it continued to travel for a distance of $2.6 \mathrm{~km}$. The volume of the initial

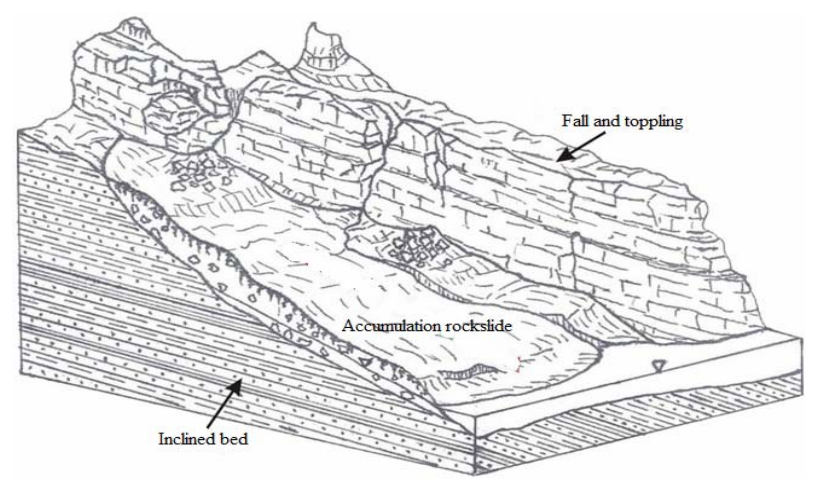

Figure 1. Showing rockfall and toppling, inclined bedding and accumulated rockslide, modified after [2].



Figure 2. Location map showing Jiwei Shan, Wulong County, Chongqing City.

fall has been estimated as 2.5 - 3.0 million cubic meters, it includes mainly rocks consisted of limestone originated from an elevation of approximately $1600 \mathrm{~m}$ which "dragged along a great quantity of limestone blocks". The release of the rock mass was apparently facilitated by fractures running parallel and perpendicular to the slope face. The rockslide closed a local iron ore mine, buried 87 miners; students and their parents and villagers, destroyed the water pipes and stoped the electrical service, closed the local road and caused the evacuation of houses that were threatened by another one. The lake that created at the posterior due to the rockslide, making it perhaps the most catastrophic single rockslide event recorded in the area.

The study area has a complex geologic structure, with variable lithologic characters, karst environment, undulating mountains, and obvious elevation differences. The geological disaster, endangering the residents, houses and properties cost billions of yuans. This study presents the engineering geological and geophysical assessment of the June 5, 2009 Jiwei Shan rockslide and to find out the factors considered to be potential triggers of the rockslide. The study is achieved through conducting regional and detailed geological fieldwork, tectonic study, photointerpretation, degree of weathering, laboratory test analysis of rock samples collected from the rockslide repsenting Maokuo and Qixia Groups and Jialingjiang Formation for comparison, study of thin sections and Scanning Electron Microcope (SEM) and application of Vertical Electrical Sounding (VES).

\section{Methods of Investigations}

Prior to the visit a detailed desk study of the geology of 
the study area had been undertaken, using geological maps (scale 1:500 000) and Google earth Image. On the visit a walkover survey was done to the rockslide area and it's vicinity to examine the geological exposures, geological structures, strikes and dips, fractures and to ascertain if there were any geological factors relevant to the occurrence of the rockslide. During the investigation: geological maps were studied and used during the fieldwork, degree of weathering and bedding planes were determined, the vertical sequences of the lithology are investigated from the available exposures along the eastern face of Jiwei Shan, the sliding surface is identified and the verification of the location of the weathered and fresh bedrocks would be carried out. During the fieldwork rock samples were collected for laboratory tests to verify their physical properties, texture, colours, mineral composition and cementing materials. Representative thin sections of the rock samples have been studied petrographically and by Scanning Electron Microscope (SEM) in order to know their mineral composition, investigate their microstructural features and degree of weathering of the limestone. Two profiles of Vertical Electrical Sounding (VES) were carried out on the surface of Jiwei Shan parallel and perpendicular to the rockslide axis in order to study the subsurface of Jiwei Shan.

\section{Geology}

Geology of the study area consists of rocks of the Silurian, Permian and Triassic Systems. The general lithology is arranged chronologically from younger to older as follows: The Quaternary Deposits (Q), Jialingjiang Formation (Lower Triassic Formation $T_{1} \mathrm{j}$ ), Maokou Group (Upper Paleozoic, Early Permian System $\mathrm{P}_{1} \mathrm{~m}$ ), Qixia Group (Upper Paleozoic, Early Permian System $P_{1} q$ ), Liangshan Group (Lower Permian System $\mathrm{P}_{1} 1$ ) and Hanjiadian Group (Medium Silurian System $\mathrm{S}_{2} \mathrm{~h}$ ) (Figure 3).

\subsection{The Quaternary Deposits (Q)}

It's composed of recent, loose and soft deposits, formed

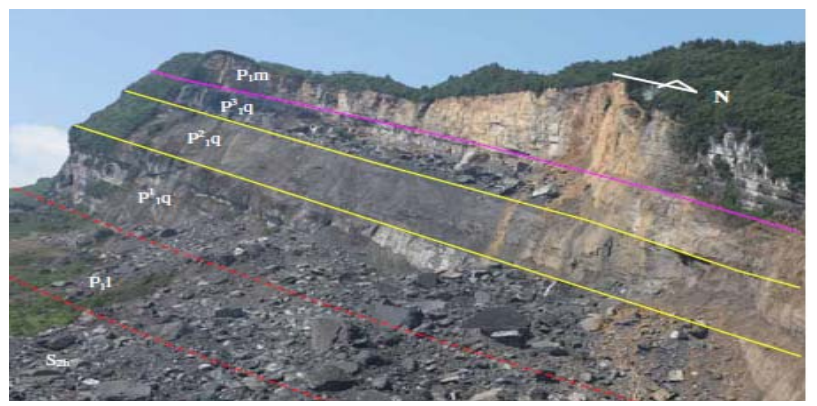

Figure 3. Lines show the boundaries between the different rock strata of Jiwei Shan rockslide [3]. The Lower Triassic Formation is not shown here because it is located in the west part of Jiwei Shan. by the streams, winds, running water and earth filled by man. The loose deposits are widely distributed on the slopes bodies between erosion surfaces and the bottom of the slopes.

\subsection{Jialingjiang Formation (Lower Triassic T1j)}

The Jialingjiang Formation is the main karst strata; it's composed of light grey, middle-thick bedded with intercalated thin-bedded limestone and argillaceous limestone. It dips $49^{\circ} \mathrm{N}$. It's strong and tough, it has three sets of joints, divided the limestone into blocks nearly equal in size. While, the silicified shale limestone is dark in colour, hard and tough and contains bituminous coal. It dips $34^{\circ} \mathrm{N}$ and strikes E. The fractures coinciding with the bedding plane trend $\mathrm{N}$ and dip $34^{\circ}$ while, the vertical ones strike $90^{\circ} \mathrm{E}$ and dip $0^{\circ} \mathrm{N}$.

\subsection{Maokou Group (Upper Paleozoic, Early Permian System $\left.\mathbf{P}_{\mathbf{1}} \mathbf{m}\right)$}

This Group is inhomogeneous, it forms the uppermost layer of the Jiwei Shan (Figure 3) and it composes of: highly weathered micrite (characterized by deep caves, grikes, rockhead, sinkholes and erosion cracks), Highly weathered argillaceous micritic limestone, three varieties of fine-grained limestone (the first variety characterized by alternating weathered lower layer has high ability to disintegrate to soil compared to the light upper layer; it dips $21^{\circ} \mathrm{N}$ and strike $290^{\circ}$ with a thickness of $150 \mathrm{~cm}$. The second variety is dissected by vertical and horizontal fractures which lead to form small blocks of rock mass. The general dipping of the rock coincide with the general orientation and the dipping of the whole rock mass. The third variety is highly weathered and light to yellow in colour. It represents the collapsed caves of the limestone), Limonite limestone is very hard; pinkish; composed of round crystals and has dark lenses of iron oxides, moderately weathered and light coloured aargillaceous micrite, and highly weathered argillaceous limestone and shale; white; grey and pinkish coloured; soft and porous.

\subsection{Qixia Group (Upper Paleozoic, Early Permian System $\left.P_{1} q\right)$}

Deep grey to black in colour, thick and blocky, very hard to hard limestone layer, contains cherty nodule, knotted, and eye-like limestone containing firestone (flint) are not uncommon. At Jiwei Shan; Qixia Group (Figure 3) is classified by [4] chronologically from top to bottom into three subgroups (layers) according to their colours and strength. The rupture surface was along this weak layer.

\subsubsection{Upper Layer $P^{3}{ }_{1} q$}

It represents the uppermost layer of Qixia Group; it 
composes of two rock types: the dark grey, slightly weathered and hard fine-grained silicified limestone with a thickness of about $20 \mathrm{~m}$ and silicified limestone composed of cryptocrystalline quartz occurs chiefly as nodules in the limestone. It occurs probably as a result of chemical changes in compressed limestone, during the process of diagenesis. The limestone embedded in weathered shale, its degree of weathering decreases towards the center of the rock mass.

\subsubsection{Middle Layer $P^{2}{ }_{1} q$}

The stratum of this layer has gentle dipped slope, it's densely vegetated (the eastern wall side of Jiwei Shan). It is comparatively weak and strongly weathered compared to the overlain beds and it consists of two rock types: a highly weathered, thickly bedded and dark grey shale limestone with clear fissility, overlain by highly weathered shale and bituminous interlayer and crushed pinkish limestone. The rock represents the sliding surface of the rockslide. The shale limestone fissility can be scratched by finger and most of the slided rocks that contained shale are crushed and disintegrated into layers due to this discontinuity. It's worth to mention that, most of the rocks of the scrap are characterized by having a layer of shale with different thickness. This indicates that, shale represents the weakest layer from which the rockslide has been triggered. The shale quartz limestone is grey to dark grey, intercalated with shale with a clear facility which easily scratched by a hammer. The rock is highly weathered and show clear traces of fractures and remains of infilling light yellow clay. The wall of the fracture shows some alteration and small water cavities (etching).

\subsubsection{Lower Layer $\mathbf{P}^{1} \mathrm{q}$}

This layer is composed of limestone intercalated with white to grey, hard and compact shale and silicified mud. In another place, it's alternating with shale; each layer is about $5 \mathrm{~cm}$. The mudstone is resisting to weathering and large boulders of mudstone are not uncommon. The highly silicified and compacted limestone and mudstone are resisting to weathering and crushing.

\subsection{Liangshan Group (Lower Permian System $\left.\mathbf{P}_{\mathbf{1}} \mathbf{l}\right)$}

It's situated below Qixia Group; it consists of gray and greyish-black argillaceous shales, carbonate mudstones, bauxites and claystones with iron ores inside. The iron manto was explored in the middle part of this layer.

\subsection{Hanjiadian Group (Medium Silurian System $\left.\mathrm{S}_{2} \mathrm{~h}\right)$}

It's composed of sand and marine shale, unconformably overlain by Liangshan Group. Studies suggested that the source of ore forming materials was from this group. It is rich in bauxite and hydromica.

\subsection{Petrography}

The polarized optical microscope was used to study the rock samples of Jiwei Shan. This study was conducted on all the samples. Microscopy results shed light on the composition, texture, structure, porosity and microcracks of the rocks (Figure 4).

\section{Tectonic and Setting}

Jiwei Shan is located at the northwestern flank of the Zhaojiaba anticline, a monoclinal fold. It's a south-north dipping limb of an anticline fold. The karst geopathologies occur in large scale on the mountain. The limestone beds include the exposed rocks while, marine shale covers the lower bed of the mountain. There is a clear cliff in the eastern part of Jiwei Shan, the North Slope is gentle dipping and the Western is slight. The way of the mountain extension is corresponding to the tectonic line. The top of the mountain is formed due to the effect of weathering and erosion.
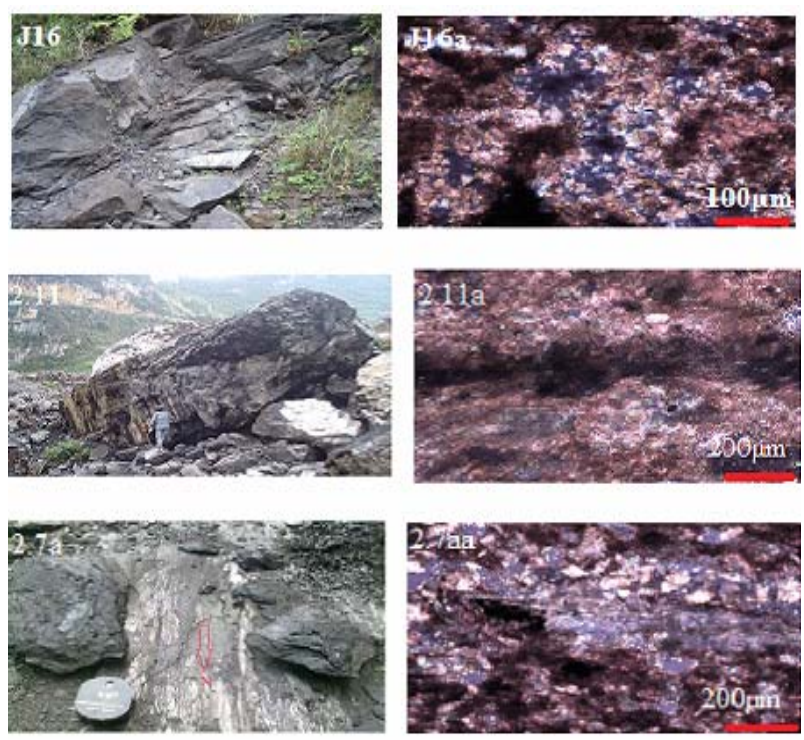

Figure 4. Jialingjiang Formation showing: (J16) hard and tough silicified shale limestone contains traces of coal and (J16a) thin-section photomicrograph in XPL showing calcite, silicious material with undulose extinction and micro structure of mud. Maokou Group: (2.11) highly weathered argillaceous limestone and shale and (2.11a) thin-section photomicrograph in XPL showing irregular, solution seam and microcrystalline calcite. Qixia Group: (2.7a) shale bituminous limestone with clear fissility, smooth, and slickenside surface resulted due to the frictional movement of the sliding rock mass. The red arrow indicates the direction of the rockslide and (2.7aa) thin-section photomicrograph in XPL showing grooves, scratches and completely flattened, forming an intensified bedding-parallel lamination. 
Tectonically, it belongs to the Yangtze platform, which is a tectonic steady region of the southern part of China. It experienced several tectonic movements from the Cambrian to the Cenozoic [6]. During the Cambrian and Silurian period, a transgression-regression sediment sequences were detected by many researchers in this region, which mainly composed of shallow marine carbonate rocks. Guangxi Movement, which happened in the Late Silurian period, leads to uplift the study area to land. The sediment of Devonian and Carboniferous is missing and full records of the sedimentary sequence in the Permian and Triassic periods were detected. The area of study went into platform mobile period in the beginning of the Late Triassic Epoch. The sedimentary rocks (from Cambrian to Jurassic) were folded and fractured by Yanshan Movement and established geologic pattern at the end of the Jurassic period. The stratum of the nominated area is composed of anticline (extending north- south) and syncline.

The tectonic zone has offered a favourable setting for the Jiwei Shan rockslide, and has controlled the movement pattern and direction. According to the field investtigations, the tectonic of the study area imposes controls on the rockslide in many ways: created favourable terrain, provided sufficient rockslide prone materials such as highly weathered limestone and shale, weak rocks, created very steep beds which reduced the stability of the rock slope and highly fractured beds. The several sets of fractures, the gradual weakening of the rock mass (perhaps by chemical and mechanical weathering or dilation from unloading by continual erosion) have lowered the rock mass strength below the prevailing gravitational induced stress and allowed failure to occur.

\section{Fracture Orientation}

The study area experienced several tectonic movements from the Cambrian to the Cenozoic lead to the formation of Jiwei Shan fractures. On Jiwei Shan, two sets of steeply dipping fractures developed in the strata more or less parallel and regularly spaced, sometimes their spacing varies from narrow to wide [7]. One set trends EW and dips at $71-80^{\circ}$ between $\mathrm{S} 10^{\circ} \mathrm{E}$ and $\mathrm{S} 10^{\circ} \mathrm{W}$. It is smooth and flat with a high persistence of $10-20 \mathrm{~m}$ and an interval of $1-3 \mathrm{~m}$. The back scarp of the rockslide traced along the strike. Set two trends SN directions (between $\mathrm{N} 15^{\circ} \mathrm{W}$ and $\mathrm{N} 20^{\circ} \mathrm{E}$ ) and dips at $75-79^{\circ}$, near vertical, towards $75-110^{\circ}$. It is long and has very high persistence and good continuity; thereby, it formed the western boundary of the rockslide, almost parallel to the eastern cliff. With reference to the field survey, these two sets of fractures are almost perpendicular to each other, which cut the strata into blocks. The strength of a discontinuous rock mass is governed by the strength of the intact blocks and the freedom of the blocks to rotate and slide under different stress conditions [8]. Thereby, once the intact blocks in the source area had well free sliding faces and enough sliding spaces, they are easy to be triggered by rainfall, medium to high intensity earthquake, other man-made unfavorable activities like explosion or excavation. Most of the studied fractures located towards the north of Jiwei Shan are described as has clear visible cavities; very few were tight or partly opened. Mostly, they are empty, little is filled by clays and/or carbonates and they are wet. Their surfaces are smooth, weathered, wavy or rough.

Many vertical fractures were eroded on the surface, under the soil and in deep beds by the rainwater, soil solution with $\mathrm{CO}_{2}$ and the action of microorganism. Figure 5 shows contours of dominant fractures sets obtained on a lower hemispherical equal area projection for different fractures data. Because only the mean orientations were used and also the chance of having blind zone fractures are very minimal, bias correction procedures for orientation they were not applied in this work in representing the orientation distribution of fracture sets. The effect of orientation bias correction on the estimation of mean orientation for the fracture sets dealt with in this work would be negligible.

\section{Hydrogeological Feature}

The main supply of underground water in the study area is the atmospheric rainfall and partial running surface water from stagnant agricultural activities on the top of Jiwei Shan. The occurrence of water in the bedrocks in the study area can be classified into: fracture bearing water, karst water and pore water. The fracture water is mainly distributed in the fractured bedrocks of Maokou and upper and Middle Layers of Qixia Groups.

Jiwei Shan rocks are thick; inhomogeneous, having more lime and piping. In the Maokou calcareous rocks, the karst water is produced from the areas of irregular
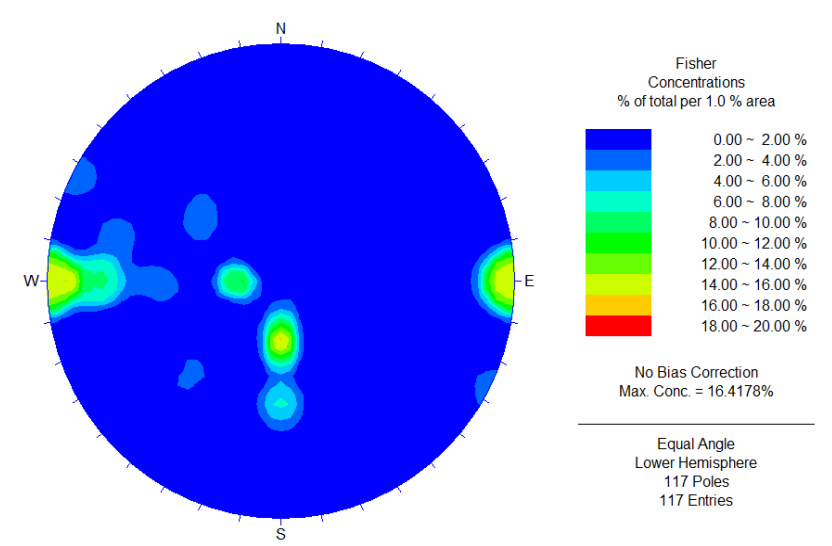

Figure 5. Contour plots of dominant fracture sets on a lower hemispherical equal area projection for fractures of Jiwei Shan. 
limestone in which erosion has produced fissures, sinkholes, underground streams, and caverns. The karst grows and the output of water is very rich and the water permeability is really strong, water passes through fractures, crevices, and cavities, dissolves the limestone very slowly, enlarging the network of passageways. During the rainy season, the water seeps from the eastern face of Jiwei Shan where the caves and large fractures are situated. Similarly, the slope contains intensive vegetation cover that would suggest the presence of water. Based on this information it is inferred that the slope is mostly wet with the water level especially Maokou and upper and middle layer of Qixia Groups. Assuming that groundwater flow for the eastern slope is controlled by fracture permeability, the discontinuity network derived for this study, although simplified, suggests that flow would be parallel to bedding in the upper parts of the slope until it reaches the flow barrier created by the slope. Here pore-water pressures and flow may dissipate through the more heavily fractured rock mass.

\section{Weathering}

The intensive rainfall and fluctuation of temperature during the winter and summer accelerated the process of weathering and hence resulted in the deterioration and weakening of limestone quality. The development of weathering and alteration in the rocks occurs through changes in physical properties of the rocks. The style and rate of weathering are controlled by fractures, porosity and permeability of the rocks, which governs the ease with which water can enter and the weathering products be removed. The rocks at the surface are in a continuous state of decay while those below decompose by solution of elements in water, which enter through discontinuities, bedding and cross-bedding. The weathered zone may be deep because the discontinuity continues to great depth; this is detected in the Middle Layer of Qixia Group.

Carbonation is the chemical weathering of limestone and dolomite rocks by rainfall. Water vapour in the air reacts with carbon dioxide to form carbonic acid, and then reacts with the calcium and calcium/magnesium carbonate. The mineral changes and becomes soluble in water. The rock dissolves in rainwater and is washed away according to the following equations:

$$
\begin{gathered}
\mathrm{CaCO}_{3}+\mathrm{CO}_{2}+\mathrm{H}_{2} \mathrm{O} \leftrightarrow \mathrm{Ca}^{+2}+2 \mathrm{HCO}_{3}{ }^{-} \\
\mathrm{CaMg}\left(\mathrm{CO}_{3}\right)_{2}+2 \mathrm{CO}_{2}+2 \mathrm{H}_{2} \mathrm{O} \leftrightarrow \mathrm{Ca}^{+2}+\mathrm{Mg}^{+2}+4 \mathrm{HCO}_{3}{ }^{-}
\end{gathered}
$$

Carbonic and Humic acids trickle along the fractures of limestone widening them through the weathering processes of carbonation and solution. Rates of weathering are increased by acid rain. In winter, frost shattering further weathers the limestone.

\section{Degrees of Weathering}

The weathering of Jiwei Shan limestone has encountered in significant problems involving the weakening of rocks and the unstable slopes, it generally shows some anomalous engineering characteristics in comparison with fresh rock in the adjacent areas. Variation in weathering grade (Table 1) of limestone resulted in various physical properties. Jiwei Shan limestones range in their degree of weathering from slightly, moderately to highly weathered corresponding to grade II, III and IV, respectively. Jialingjiang Formation characterized by slightly to moderately (II to III) weathered limestone, Maokou Group range from slightly to highly (II to IV) weathered limestone and Qixia Group from moderately to highly (III to IV) weathered limestone.

\section{Scanning Electron Microscope (SEM)}

The microcracks, micropores and grain size of Jiwei Shan limestone Groups were studied and the influence of the factors mentioned above on the rock is assessed. EDAX results evidenced the dominant $\mathrm{Ca}$ and $\mathrm{Si}, \mathrm{Mg}, \mathrm{K}$, $\mathrm{Al}, \mathrm{Fe}, \mathrm{Bi}$ and $\mathrm{Rb}$ are present in small quantities.

For microscopic observation, about twelve limestone samples representing Jialingjiang Formation and Maokou and Qixia Groups were selected from different grades of weathering. The study of the SEM photomicrographs showed that (Figure 6) the increase in microcrack propagations and size of micropores in limestone indicated the increases in the weathering grade from grade II (slightly weathered rock) to grade III and IV (moderately

Table 1. Definitions of the degrees of weathering, adapted

\begin{tabular}{|c|c|c|}
\hline Grade & Term & Typical Characteristics \\
\hline I & Unweathered & $\begin{array}{l}\text { Unchanged from original state. No } \\
\text { evident microfracturing. Slight } \\
\text { discolouration on major discontinuity } \\
\text { surfaces }\end{array}$ \\
\hline II & Slightly weathered & $\begin{array}{l}\text { Slight discolouration, slight weakening. } \\
\text { Weathering penetrates through most } \\
\text { discountunitues }\end{array}$ \\
\hline III & Moderately weathered & $\begin{array}{l}\text { Considerably weakened, penetrative } \\
\text { discolouration. Large pieces cannot be } \\
\text { broken by hand }\end{array}$ \\
\hline IV & Highly weathered & $\begin{array}{l}\text { Significantly weaker than the fresh } \\
\text { rock. Easily brekable with hand }\end{array}$ \\
\hline $\mathrm{V}$ & Completely weathered & $\begin{array}{l}\text { Original texture is present. All mi- } \\
\text { crofractures tend to be open. Losses } \\
\text { most of strength of fresh rock }\end{array}$ \\
\hline VI & Residual soil & $\begin{array}{l}\text { Soil derived by in situ weathering but } \\
\text { retaining none of original texture or } \\
\text { fabric }\end{array}$ \\
\hline
\end{tabular}
from [9]. 
and highly weathered rocks, respectively). The increase in microcrack length was coupled with the increase in width of the cracks as observed using SEM. Based on the effect of weathering on pore geometry of Jiwei Shan limestone, the porosity values increase with the degree of weathering from grade II to grade IV. There were no significant changes in the porosity values of the silicified and cemented limestone. According to [10], the pore volumes of the limestone increase proportionally with weathering stage.

\section{Laboratory Tests}

\subsection{Specific Gravity and Bulk and Dry Densities}

The specific gravity and bulk and dry densities of the Jialingjiang Formation and Maokou and Qixia Groups limestone, were determined. The mean values of the specific gravity and bulk and dry densities fall within the normal range given to the limestone (Figure 7).

\subsection{Porosity}

The mean porosity values of the Jialingjiang, Maokou and Qixia limestones collected from Jiwei Shan recorded
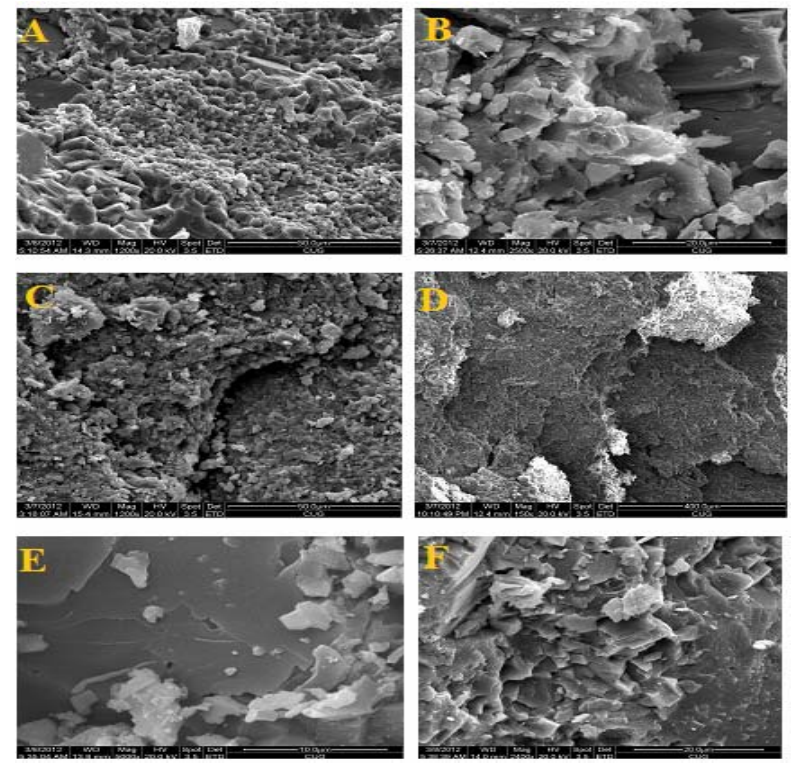

Figure 6. SEM photomicrograph showing: (A) low porosity slightly weathered limestone and (B) microcracks linking pre-existing pores and en echelon microcracks in porous moderately weathered limestone, (Maokou Group). (C) Large scale surface scaling in highly porous and highly weathered shale limestone with clear fissility and (D) large scale surface scaling in, porous and highly weathered shale limestone with clear fissility (Qixia Group). E. slightly weathered limestone with a high density and (F) Unweathered silicified shale limestone with a high density, (Jialingjiang Formation). different values. The shale and bituminous interlayer of Qixia Group has recorded the highest porosity while limestone of Maokou showed relatively moderate values (Figure 8). The higher values of porosity of Qixia Group limestone attributed to the composition of the rock and the low porosity of the Jialingjiang limestone can be attributed to the compaction and silicification. The study of the thin sections and SEM indicate the effect of solution in the limestone of Maokou and Qixia Groups is enlargement of the pores and fractures that cause more water movement to shale and bituminous interlayer of Qixia Group. Some types of porosity were identified in the studied limestones and illustrated in Figure 9.

\subsection{Water Absorption and Saturated Water Absorption Capacities}

The water absorption and saturated water absorption capacities of the Jialingjiang, Maokou and Qixia limestones collected from Jiwei Shan were obtained. The intent of this task was to quantify whether there is a correlation between the natural porosity and the water level absorption attained for the selected rocks. The shale and bituminous

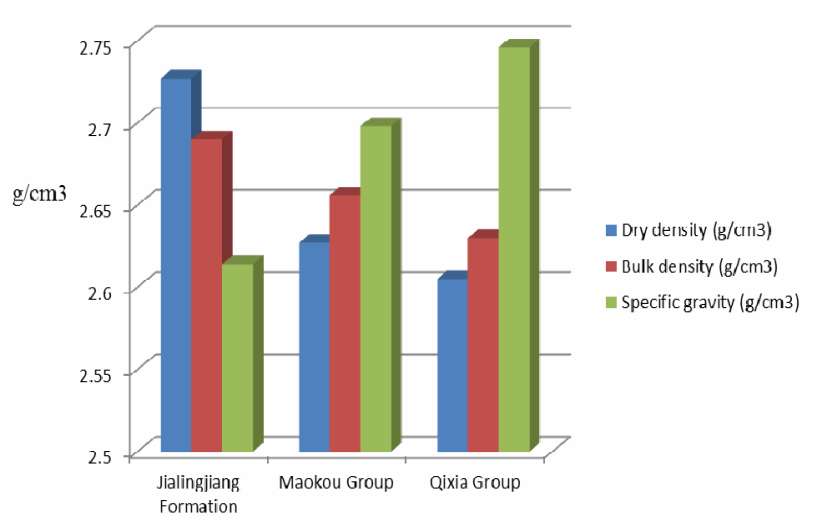

Figure 7. Showing the average specific gravity, dry density and bulk density of Jiwei Shan limestone.

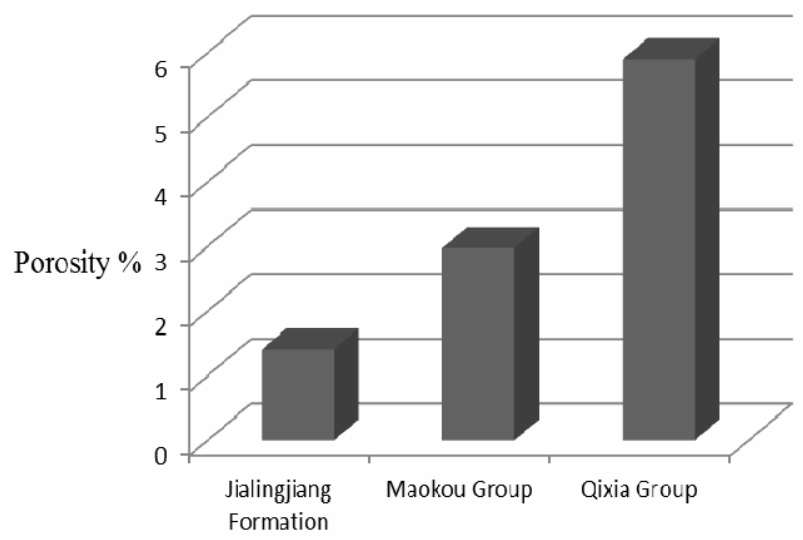

Figure 8. Showing the average porosity of Jiwei Shan limestones. 
interlayer of Qixia Group showed the highest ability to absorb water $(3.76 \%-0.04 \%)$ compared with Jialingjiang, Maokou limestones. Maokou limestone gave $(2.51 \%$ - $0.26 \%)$ and Jialingjiang limestone recorded $(0.24 \%$ $0.12 \%)$. There is significant correlation between the porosity percentage and the water absorption in Jiwei Shan limestone (Figure 10). The shale and bituminous interlayer of Qixia Group has relatively higher porosity therefore, they have the tendency to absorb significant amounts of water compared with Maokou limestones and Jialingjiang.


Figure 9. SEM photomicrograph showing: (A) Fenestral porosity formed by dissolution of the cement or matrix sometimes caused by enlargement of microfratures. This type of porosity was observed easily in the hand specimens. Fracture porosity formed by fracturing, and some of them are cemented. (B) Intraparticle porosity within individual particles or grains is generally primary, but forms rarely by dissolution of cement or matrix. (C) Interparticle porosity between grains and/or particles forms via leaching or matrix or cement. (D) Inter- and/or intragranular porosity enlarged somewhat by dissolution around the original pores.

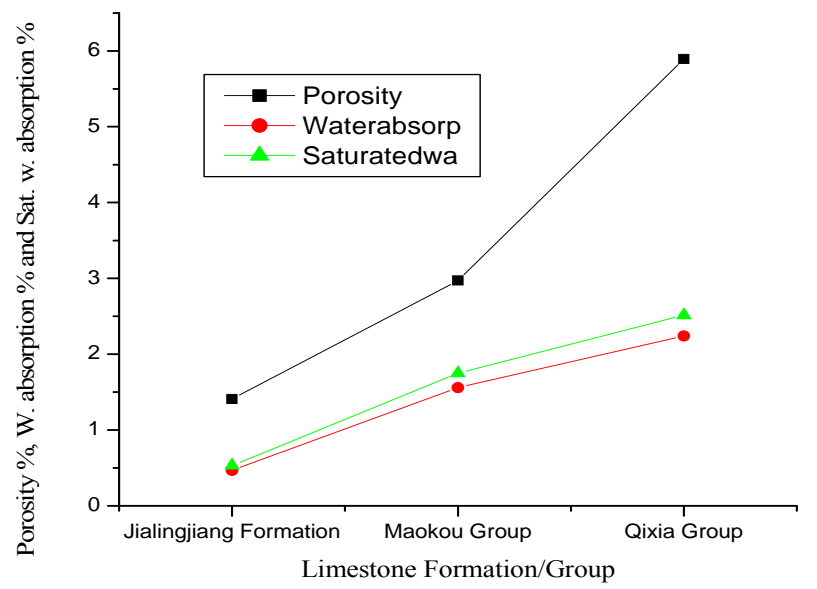

Figure 10. The mean porosity, water absorption capacity and saturated water absorption capacity of Jiwei Shan limestons.

\section{Karst Processes}

Jiwei Shan Karst is characterized with caves, grykes, dissolution cracks and rockheads which display a long history of geological evolution and an unusual range of karst formations. Karst features mostly develop in association with discontinuity planes (fractures) by progresssive dissolution of the carbonates leaving a soft and porous weathering residue and enlarged weathered fractures [11]. Karst of Jiwei Shan has suite of fractures and voids cut into the surface and rock mass of the limestone. Dissolution of rock occurs on exposed outcrops, at the top of Jiwei Shan beneath soil, and along the fractures (Figure 11). There are many structures formed in Maokou Group due to the process of weathering including caves located in the eastern cliff of Jiwei Shan, Sinkholes formed by dissolution weathering of the carbonate minerals, Grykes are observed on the top of Jiwei Shan, their most dominant system runs almost south to north; it stretches for thirties of meters until they suddenly terminate or lost beneath superficial deposits and Rockheads are subsoil dissolution at the soil/rock interface creates a clean rockhead without the gradual transition through a weathering sequence in insoluble rocks, it's extremely irregular on Jiwei Shan karstic bedrock. The structures formed in Jiwei Shan karst profiles tend to be more complex in dipping limestone.

\section{Geoelectrical Soundings}

Two vertical electrical soundings (VES) (Jiwei Shan1

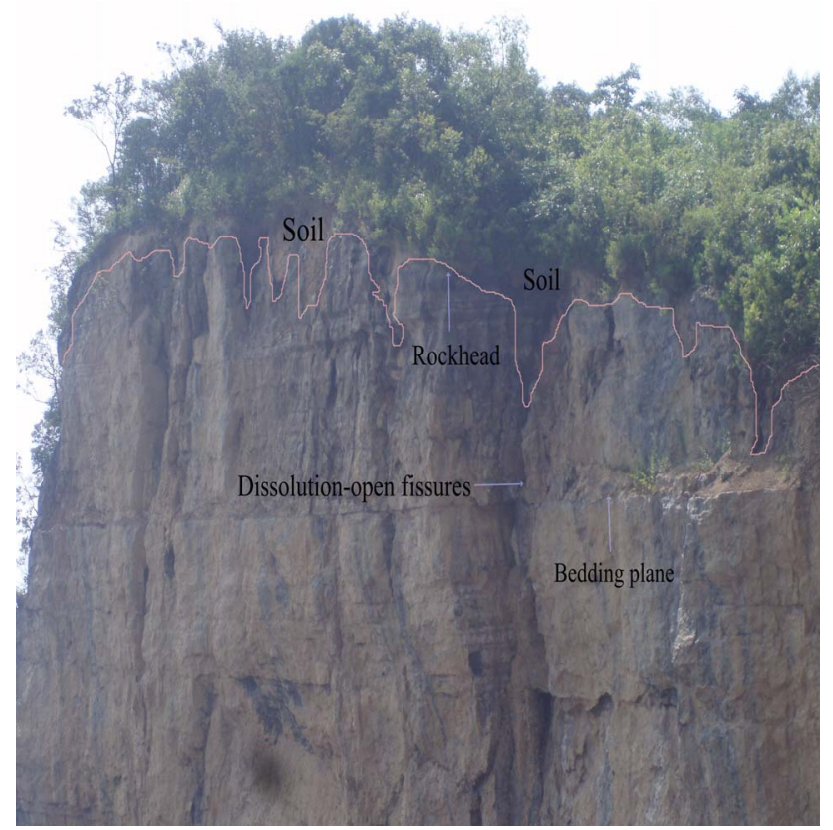

Figure 11. Rockhead, dissolution-open fissures and bedding plane on the wall ofJiwei Shan rockslide platform. 
and Jiwei Shan2) were carried out on the top of Jiwei Shan using a Schlumberger array to investigating the karst and displays lithological and slope deformation features. Jiwei Shan1 is almost parallel and west of the rockslide platform and trending $\mathrm{S}-\mathrm{N}$, the second is perpendicular to it. $180 \mathrm{~m}$ electrode spacing was selected to reach a maximum depth of investigation of about $60 \mathrm{~m}$.

Jiwei Shan1 (Figure 12) produced four different resistivity of layered rocks which are clearly defined by their different resistivity layers at the various depths in inverted resistivity sections as follows:

A thin undulating subsurface layer with a comparatively low resistivity values to an approximate depth of about $6 \mathrm{~m}$. This layer of low resistivity is typical of weathered limestone of the underlying rocks in the area. The wavey pattern is probably due to the action of karst process and weathering.

The area between $244-260 \mathrm{~m}$ along the $\mathrm{x}$-axis in the south of the profile shows vertical increase in resistivity with depth from (126 - $1450 \mathrm{ohm} . \mathrm{m})$, this area represents the northern part of the platform in which the karst and weathering processes are active due to the presence of limestone discontinuities and dissolution-open fissures from the surface to the bottom. The difference in weathering degree is probably due to the inhomogeneity of the limestone.

An intermediate resistivity layer at the intermediate depth zone, which could represent slightly to moderately weathered limestone material, is observed afterwards. The depth of this layer ranges between (1297 - $1290 \mathrm{~m}$ ) and has a comparatively moderate to high resistivity in the range between (642 - 3273 ohm.m).

A thick layer with a comparatively high resistivity is also observed below the two layers of low to moderate to high resistivity limestone resistivities. This relatively high resistivity bedrock layer, possibly represent the fresh limestone material with competent structural patterns.

Figure 13 displays two features, one is in the east and the second is in the west. The eastern part of the profile includes two resistivity zones. One is given by the presence of high surface resistivity anomaly ( $>1500$ ohm.m) and it points to the presence of compact limestone, it's located probably between two vertical discontinuities (fractures) widen by dissolution (point 332 and 357 along the $\mathrm{x}$-axis), their depths range between $5-15.85 \mathrm{~m}$. The second layer is characterized by relatively low resistivity (122 - 671 ohm.m) and depth start from $5 \mathrm{~m}$ and extends to the end of the profile and it indicates the presence of weathered limestone. The body that situated at the medium depth within the second layer is characterized by the lowest resistivity value (122 - 286 ohm.m), it's probably a buried cave.
The western part of the profile includes three resistivity zones. A subsurface layer with low resistivity (22-122 ohm.m) is located between $379-395 \mathrm{~m}$ (along the x-axis) and extends to a depth of $8 \mathrm{~m}$. The middle layer characterized by medium resistivity values (122 - 671 ohm.m) and engulfs the upper layer. The depth of the middle layer reaches to about $15.85 \mathrm{~m}$ and it's acting as small basin within the profile based on its lower resistivity in relation to the background resistivity on the profile. The first and the middle layer represent highly to moderately weathered limestone. The third layer characterized by higher resistivity ( $>1500$ ohm.m).

\section{Discussion}

The lithology of Jiwei Shan has great influence on the nature, rate of weathering and rockslide process. The petrographical study revealed that, the limestones of Jiwei Shan are mixtures of several lithologies and beds, contain substantial amounts of impurities and may behave weakly according to their contents and have a more complicated composition, structure and texture. Therefore, the rate and nature of geomorphological processes, characteristics of the exposed and subsurface materials of the rockslide process and the catastrophic events has a direct correlation of lithology. The limestone of Jialing jiang Formation is generally hard and tough compared to the other two Groups. Maokou Group characterized by karst caves, grikes, sinkholes (solution, collapse, dropout and buried) and erosion and dissolution cracks. The bed

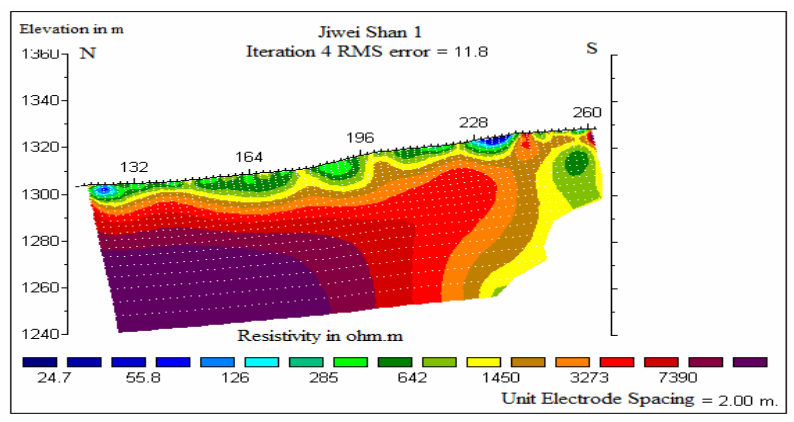

Figure 12. 2D VES section along Jiwei Shan rockslide.

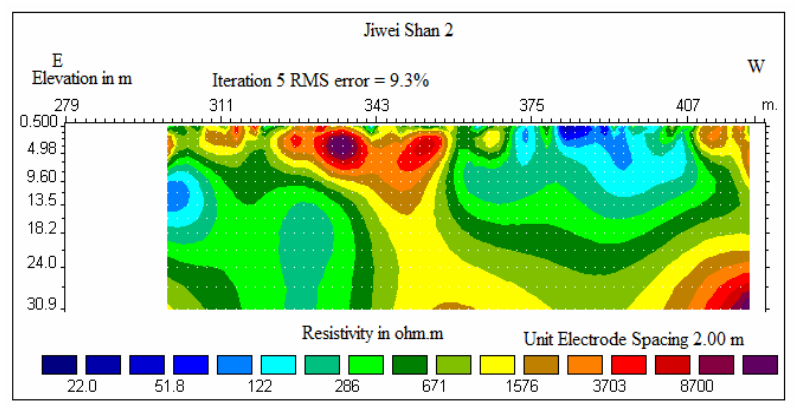

Figure 13. 2D VES section across Jiwei Shan rockslide. 
surface is a gentle inclined slope of $30^{\circ}$ which is densely vegetated by various types of plant species. The layer is highly fractured, comparatively weak and highly weathered. This Group is inhomogeneous; it composes of limestone characterized by different mineral contents. The fine-grained silicified limestone of the Upper Layer $\left(\mathrm{P}^{3}{ }_{1} \mathrm{q}\right)$ of Qixia Group is played as a medium of transmitting fluids coming from the overlain layers to the Middle Layer $\left(\mathrm{P}^{2} \mathrm{q}\right)$, leading to increase the degree of weathering and reducing the strength of the shale and bituminous interlayer. The dark gray shale limestone member of the middle layer is not affected like the below situated shale and bituminous interlayer. The latter is highly weathered and it represents the sliding surface of the rockslide. The stratum of this layer has gentle dipped slope, it's densely vegetated. The mud intercalated limestone of the Lower Layer $\left(\mathrm{P}^{1}{ }_{1} \mathrm{q}\right)$ is hard, compact, intercalated with shale, in another place it is alternating with shale. It worked as a sub-base below the sliding surface.

Generally, the potential failure pattern of Jiwei Shan may be a linear shear failure of the highly weathered shale and bituminous interlayer with clear fissility and a single slip surface with steep gradients. Identical dips and ground fractures at the eastern and top of Jiwei Shan are prone to toppling collapse. Prior to the event, the limestone was suffering from the intrinsic destruction of its structure which leads to weakening the mechanical properties of rock masses, by weathering over time. Rainfall in the study area is quite intense and contributes significantly to the weathering of the limestones. In the Maokou calcareous rocks, the karst water is produced from the areas of irregular limestone in which erosion has produced fissures, sinkholes, underground streams, and caverns. The karst grows and the output of water is very rich and the water permeability is really strong, water passes through fractures, crevices, and cavities and dissolves the limestone very slowly, enlarging the network of passageways. Therefore, the slope is mostly wet with the water especially Maokou and upper and middle layer of Qixia Groups. Due to this reason Maokou Group range from slightly to highly (II to IV) weathered limestone and Qixia Group from moderately to highly (III to IV) weathered limestone. The study of the SEM photomicrographs showed that the increase in microcrack propagations and size of micropores in limestone indicated the increases in the weathering grade from grade II (slightly weathered rock) to grade III and IV. The increase in microcrack length was coupled with the increase in width of the cracks as observed using SEM. Based on the effect of weathering on pore geometry of Jiwei Shan limestone, the porosity values increase with the degree of weathering from grade II to grade IV.

Tectonics of the study area exerted a fundamental control on the lithology and movement of groundwater, by creating a favorable environment for triggering the rockslide. Bedding attitude and dipping situation of the beds played a great role in the occurrence of Jiwei rockslide. The two fractures sets tend to weaken the rock mass, accelerating the process of weathering, decrease the strength of the rocks and created good channels for vertical and horizontal water movement within the lithology of the slope. The monocline fold of Jiwei Shan increased the dipping of the beds and created tension fractures on the top of the southern part of Jiwei Shan. The continuous fault that located along the south side of Jiwei Shan it's probably has the responsibility of creating the intense fracturing and by a way or another it has influence on weakening the rock mass. The fracture sets of Jiwei Shan cut across the limestone of Maokou and the middle layer $\left(\mathrm{P}^{2}{ }_{1} \mathrm{q}\right)$ of Qixia beds but, do not cross through the weaker shale and bituminous limestone interlayer.

The physical tests performed on representative samples from the lithology indicate that, the relatively high porosity and elevated water absorption of shale and bituminous interlayer of Qixia Group is due to their composition and moderately to highly degree of weathering but, the medium porosity and water absorption were observed in Maokuo is attributed to the nature and cementing diagenesis of limestone. The presence of micrcracks and fissility planes in shale and bituminous interlayer of Qixia Group increases the porosity. Higher porosity increases the surface area and raises water intake capacity, thus accelerating both physical and chemical disintegration. Water replaces the soluble minerals, thereby enhancing the porous structure. Moreover, shear stress is reduced in shale and bituminous interlayer due to water absorption. The discontinuities of shale and bituminous interlayer constitute a weak plane with little shear strength that is further reduced due to the effect of water infiltration. The overlain limestone beds with their present karstic condition easily slide along the bedding and fissility planes of the shale and bituminous interlayer slope with the assisting of the tectonics of Jiwei Shan.

The VES of Jiwei Shan1 revealed the presence of limestone discontinuities and dissolution-open fissures from the surface to the bottom in the northern part of the platform and relatively, the low resistivity indicates the activity of the weathering process. Also, Jiwei Shan2 revealed fractures widen by dissolution, buried cave and small basin below the subsurface within the profile.

The layer above and below the slip surface is characterized by impermeable and low porosity silicified limestone and hard and compact mud intercalated limestone, respectively. Rainfall water infiltrates through fractures of the overlying strata saturate the shale and bituminous interlayer and do not reach the impermeable and the low porosity lower layer. The development of the rockslide is promoted by the steep dipping beds in the direction of 
the slope and by presences of two sets fractures crossing each other in almost $90^{\circ}$. Thus the highly fissile and weathered shale and bituminous interlayer limestone interface tends to become a weak plane of extreme instability.

\section{Conclusions}

The study concluded that, geology and tectonic settings have offered a favourable setting for the Jiwei Shan rockslide, and have controlled the movement pattern and direction and provided sufficient rockslide prone materials. The several sets of fractures and the gradual weakening of the rock mass perhaps by weathering have lowered the rock mass strength and allowed failure to occur.

Dissolution of rock occurs on exposed outcrops, at the top of Jiwei Shan beneath the soil, and along the fractures. There are many structures formed in Maokou Group due to the process of weathering including caves, grykes, dissolution cracks and rockheads which display a long history of geological evolution and an unusual range of karst formations. These structures weakened the rock mass of Jiwei Shan.

The highly weathered shale and bituminous interlayer limestone of the Middle Layer, Qixia Group, represents the sliding surface of the rockslide. The shale limestone characterized by clear fissility. It's worth to mention that, most of the rocks of the scrap characterized by having shale layer of varied thickness. This indicates that, shale represents the weakest layer from which the rock slide has been triggered.

The terrain and it is vicinity is still unstable, and continual rainfall on the weak and highly weathered limestone will cause another slope under the conditions which led to past instability.

\section{Acknowledgements}

The work was funded by the National Basic Research Program of China (973 Program; No. 2011CB710600), the Special Fund for Basic Research on Control of Disaster Landslide Induced by Great Engineering Projects (No. 2011CB710604, 2011CB710605 and 2011CB 710606). We gratefully acknowledge Limin Wang and Huang Rong for their assistance during the geophysical field works.

\section{REFERENCES}

[1] Q. Xu, X. M. Fan, R. Q. Huang, Y. P. Yin, S. S. Hou, X. J. Dong and M. G. Tang, "A Catastrophic RockSlide-Debris Flow in Wulong, Chongqing, China in 2009: Background, Characterization, and Causes," Journal of Landslide Landslides, Vol. 7, No. 1, 2010, pp. 75-87. doi:10.1007/s10346-009-0179-y

[2] Y. P. Yin, "Recent Catastrophic Landslides and Mitigation in China," Journal of Rock Mechanics and Geotechnical Engineering, Vol. 3, No. 1, 2011, pp. 10-18. doi:10.3724/SP.J.1235.2011.00010

[3] Z. Long, H. M. Tang, C. R. Xiong, H. Lei and Z. X. Zou, "Movement Process Simulation of High-Speed

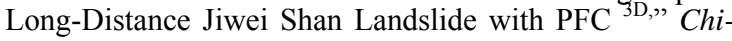
nese Journal of Rock Mechanics and Engineering with English abstract, Vol. 31, 2012, pp. 2601-2611.

[4] Y. P. Yin, P. Sun, M. Zhang and B. Li, "Mechanism on Apparent Dip Sliding of Oblique Inclined Bedding Rockslide at Jiweishan Rockslide, Chongqing, China," Landslide, Vol. 8, No. 2, 2011, pp. 49-65. doi:10.1007/s10346-010-0237-5

[5] W. Guizhen, Z. Shunmei, J. Shuyan and W. Liping, "Research into the Influence of Earthquake Induced by Three Gorges Reservoir on Seismic Risk Analysis in Downtown Areas of Chongqing," The $14^{\text {th }}$ World Conference on Earthquake Engineering, Beijing, 12-14 October 2008.

[6] The Management Bureau of the Shilin National, "Park Management Plan of Shilin (Stone Forest) Karst, Yunnan," 2005.

[7] D. U. Deere, "Technical Description of Rock Cores for Engineering Purpose," Rock Mechanics and Engineering Geology, Vol. 1, No. 1, 1963, pp. 16-22.

[8] E. Hoek and E. T. Brown, "Practical Estimates of Rock Mass Strength," International Journal of Rock Mechanics and Mining Science, Vol. 34, No. 8, 1997, pp. 1165-1186. doi:10.1016/S0148-9062(97)00305-7

[9] G. Mandl, "Rock Joints: The Mechanical Genesis," 1st Edition, Springer-Verlag, Netherlands, 2005.

[10] Anonymous, "The Description and Classification of Weathered Rocks for Engineering Purposes," Engineering Group Working Party Report, Quarterly Journal of Engineering Geology \& Hydrogeology, Vol. 28, No. 3, 1995, pp. 207-242. doi:10.1144/GSL.QJEGH.1995.028.P3.02

[11] A. Tugrul, "The Effect of Weathering on Pore Geometry and Compressive Strength of Selected Rock Types from Turkey," Engineering Geology, Vol. 75, No. 3-4, 2004, pp. 215-227. doi:10.1016/i.enggeo.2004.05.008

[12] A. C. Waltham and P. G. Fookes, "Engineering Classification of Karst Ground Conditions," Quarterly Journal of Engineering Geology and Hydrogeology, Vol. 36, No. 2, 2003, pp. 101-118 doi:10.1144/1470-9236/2002-33 